\title{
Kelola
}

\section{SUPERVISI KUNJUNGAN KELAS UNTUK MENINGKATKAN KOMPETENSI PEDAGOGIK GURU SDN CUKIL 01, TENGARAN, KABUPATEN SEMARANG}

\author{
Astiti Rahayu Argiani \\ Alumni Program Pascasarjana Magister Manajemen Pendidikan \\ FKIP-Universitas Kristen Satya Wacana \\ astitiargiani.aa@gmail.com \\ Slameto \\ Program Pascasarjana Magister Manajemen Pendidikan \\ FKIP-Universitas Kristen Satya Wacana \\ Slameto@uksw.edu
}

\begin{abstract}
The problems background in the learning process, teacher and pupils are interpedently connected to one another in the learning classroom process, it is because conversation and encounter process occurred. This learning process is not an uncommon issue. The problems are teacher has not finish classroom materials for the learning process, which cause an impact on the learning process's implementation, teacher has not developed educational learning's process, and teacher has not mastered today's technology. Based on those complications, the best solution is implementing classroom's visits supervision. The problem's formulation in this study is whether the supervision of classroom visit can improve teacher's pedagogical competence at Elementary School of Cukil 01, Tengaran. The research's purpose is to enhance teacher's pedagogical competence though the classroom visit's supervision at Elementary School of Cukil 01, Tengaran The research's type is school action research which is applied through the phase of identification of focus's areas, data gathering, analyzes and data interpretation, plan's arranging, and implementation of the action. The research's subject is ten teachers through interview and also documentary study. The data gathering's technique used though interview, observation, questionnaire, and also documentary study. The data processing's techniques are done with data classifying, data presentation and verification. The validity of test data is using data's triangulation. The research's result shows two point they are: (1) The implementation of classroom visit's supervision obtains a maximum score, that is $94 \%$ with a very good criteria $(A B)$ and minimum score is $74 \%$ with a good criteria (B). Feedback that is performed also given which is showed are mostly positive answers. (2) The teacher's pedagogical competence obtains a maximum score, that is $88 \%$ with very good criteria $(A B)$ and a minimum score is $70 \%$ with a good criteria (B).To conclude the research's result, through the classroom visit's supervision is able to improve the teacher's competence at Elementary School of Cukil 01, Tengaran. Suggestions offered, there should be continuity of the classroom visit's supervision in the school that agree by all teachers to improve the teachers' competence in the implementation of learning.
\end{abstract}

Keywords: The Classroom Visit's Supervision, Pedagogical Competence. 


\section{PENDAHULUAN}

Jabatan seorang guru merupakan profesi yang dihormati. Guru mengabdikan diri untuk mencerdaskan kehidupan bangsa dan meningkatkan kualitas sumber daya manusia Indonesia seutuhnya, yang beriman, bertakwa, berakhlak mulia, serta menguasai IPTEKS dalam mewujudkan masyarakat yang berkualitas. Inti pendidikan terjadi dalam prosesnya, yaitu situasi belajar mengajar antara peserta didik dengan pendidik yang memungkinkan peserta didik tumbuh dan berkembang sesuai dengan tuntutan nilai di masyarakat. Peran guru dalam proses pendidikan tersebut tercantum dalam Undang-Undang Nomor 14 Tahun 2005 tentang Guru dan Dosen yaitu guru adalah pendidik professional dengan tugas utama mengajar, membimbing, mengarahkan, melatih, menilai, dan mengevaluasi peserta didik pada pendidikan anak usia dini pada jalur formal, pendidikan dasar, dan pendidikan menengah.

Guna mendukung peran guru dalam proses pendidikan tersebut, maka perlu adanya kualifikasi untuk dapat menjadi seorang guru yang membimbing peserta didik. Sesuai dengan pasal 42 ayat 1,2 , dan 3 , menjelaskan bahwa:

Pendidik harus memiliki kualifikasi minimum dan sertifikasi sesuai dengan jenjang kewenangan mengajar, sehat jasmani dan rohani, serta memiliki kemampuan untuk mewujudkan tujuan pendidikan nasional. Selain itu, pendidik untuk pendidikan formal pendidikan anak usia dini, pendidikan dasar, pendidikan menengah, dan pendidikan tinggi dihasilkan oleh perguruan tinggi yang terakreditasi. (Undang Undang No 14 Tahun 2050

Seorang guru profesional harus memiliki kemampuan profesional, sosial, dan personal. Kualitas kinerja guru dinyatakan dalam Peraturan Menteri Pendidikan Nasional Republik Indonesia Nomor 16 Tahun 2007 tentang Standar Kualifikasi Akademik dan
Kompetensi Guru, yaitu Standar Kompetensi Guru dikembangkan secara utuh dari empat kompetensi utama, yaitu kompetensi pedagogik, kepribadian, sosial, dan profesional. Apabila guru telah memiliki keempat kompetensi tersebut, maka telah memiliki hak profesional. Salah satu kompetensi guru yang berperan dalam pembelajaran adalah kompetensi pedagogik, yaitu kemampuan mengelola pembelajaran peserta didik yang meliputi pemahaman terhadap peserta didik, perancangan dan pelaksanaan pembelajaran, evaluasi hasil belajar, dan pengembangan peserta didik untuk mengaktualisasikan berbagai potensi yang dimiliki. Sehingga, guru harus menguasai tidak hanya materi atau bahan ajar, tetapi juga mengetahui dan memahami perkembangan peserta didik mereka agar kegiatan pembelajaran pun dapat lebih bermakna.

Guru dan peserta didik saling berhubungan, dalam proses pembelajaran di kelas, karena terjadi dialog dan tatap muka. Proses pembelajaran tersebut tidak jarang terjadi berbagai persoalan, misalnya motivasi siswa yang rendah untuk mengikuti pembelajaran di dalam kelas, kondisi kelas yang gaduh karena belum kondusif dalam mengelola kelas, dan dampak akhirnya adalah hasil belajar (prestasi) peserta didik dibawah kriteria ketuntasan minimal (KKM). Peran guru dengan mengembangkan kompetensi pedagogik perlu diimplementasikan guna mengatasi berbagai persoalan pembelajaran di dalam kelas. Guru perlu membuat perencanaan sebelum pembelajaran dimulai agar lebih runtut dan teratur, setelah itu melaksanakannya di dalam kelas, melakukan evaluasi pembelajaran dengan pemberian remidi dan pengayaan kepada peserta didik. Tugas guru yang sangat menentukan proses pembelajaran tersebut agar tidak berjalan monoton dengan pembelajaran yang sama dari tahun ke tahun. Karena peserta didik 
yang dihadapi pun sudah berbeda dengan tingkat perkembangan yang berbeda juga.

Peningkatan proses pembelajaran yang dilakukan oleh guru sangat diperlukan, karena berdampak langsung kepada peserta didik. Salah satu upaya yang dilakukan untuk terus memantau proses pembelajaran adalah melalui kegiatan pengawasan (supervisi). Dalam Undang-Undang Sistem Pendidikan Nasional Tahun 2003, pengawasan diatur dalam bab khusus yaitu bab XIX pasal 66 yang menentukan bahwa, "pemerintah, pemerintah daerah, dewan pendidikan, dan komite sekolah/madrasah melakukan pengawasan atas penyelenggaraan pendidikan pada semua jenjang dan jenis pendidikan sesuai dengan kewenangan masing-masing". Sehingga, peran supervisi terutama dalam penyelenggaraan pendidikan yang dilakukan oleh berbagai pihak sangat penting. Melalui supervisi diharapkan dapat meningkatkan kualitas guru dalam proses pembelajaran, sehingga dapat meningkatkan kualitas siswa dan sekolah. Supervisi secara umum memberikan hal positif baik bagi guru yaitu dapat mengurai berbagai masalah yang terjadi selama pembelajaran, dan untuk pemimpin dapat meninjau langsung pembelajaran yang terjadi dan saling bertukar pikiran demi kemajuan kualitas.

Penelitian sebelumnya yang digunakan sebagai data pendukung salah satunya adalah penelitian yang dilakukan oleh Ni Nengah Widyani pada tahun 2011 dengan judul, "Teknik Supervisi Kunjungan Kelas Sebagai Upaya Meningkatkan Kemampuan dan Profesionalisme Guru SD 3 dan 10 Kesiman Denpasar". Penelitian ini bertujuan untuk mengetahui apakah teknik supervisi kunjungan kelas yang dilaksanakan dapat meningkatkan kemampuan dan profesionalisme guru dalam melaksanakan pembelajaran. Penelitian ini dilaksanakan dalam dua siklus dan mengalami peningkatan pada setiap siklus. Hasil yang diperoleh dari penelitian ini adalah supervisi kunjungan kelas dapat meningkatkan keterampilan dan profesionalisme guru SD No 3 dan 10 Kesiman, Kecamatan Denpasar Timur, Kota Denpasar, Provinsi Bali.

Paparan mengenai peran pemerintah dalam pendidikan perlu diapresiasi. Namun, pada kondisi nyata masih terdapat masalah dalam pendidikan khususnya peran pendidik sebagai pelaksana proses pendidikan. Hal ini ditunjukkan data yang diperoleh dari LPMP (2012) tercatat 1.840 guru di Jawa Tengah tidak lulus Uji Kompetesi Awal (UKA) sertifikasi tahun 2012 dalam seleksi yang dilaksanakan tersebut. Total guru yang mengikuti UKA di Jawa Tengah adalah 37.211 pendidik, terdaftar 35.371 pendidik saja yang dinyatakan lulus. Hal yang sama juga terjadi di Semarang, terdapat 79 guru yang tidak lolos UKA sehingga tidak dapat mengikuti proses selanjutnya yaitu pendidikan dan latihan profesi guru (PLPG). Kondisi tersebut menunjukkan bahwa guru sebagai pelaksana proses pendidikan belum dapat menembus UKA dimana sebagian besar soal yang diberikan mencakup empat kompetensi guru (www.lpmpjawatengah.go.id).

Berdasarkan hasil studi pendahuluan, permasalahan yang terjadi di Jawa Tengah dan Semarang tersebut, juga terjadi di SD Negeri Cukil 01, Kecamatan Tengaran, sebagian besar guru belum melakukan perencanaan proses pembelajaran, sehingga berdampak pada pelaksanaan pembelajaran yang masih berpedoman salah satu buku tanpa menggali dari sumber lainnya yang relevan serta implementasi berbagai model dan metode pembelajaran masih belum dikembangkan. Dampaknya adalah pembelajaran menjadi monoton dengan berbagai perkembangan yang terjadi pada masing-maisng peserta didik yang belum 
mendapat perhatian dan berakhir dengan gaduh di dalam kelas. Evaluasi yang dikembangkan oleh guru sebagian besar menggantungkan dari pekerjaan rumah atau tugas yang ada di dalam buku. Sehingga, penilaian terkesan hanya menitikberatkan pada kognitif peserta didik tanpa disertai dengan indikator penilaian yang jelas dari guru. Siswa belum memahami penggunaan teknologi informasi dalam pembelajarannya. Hal ini, karena guru sendiri pun sebagian besar juga belum menguasai peranan teknologi informasi dalam pendidikan. Permasalahan yang terjadi merupakan masalah karena kurangnya pengembangan kompetensi guru dalam mengelola pembelajaran di dalam kelas.

Berdasarkan latar belakang masalah tersebut, peran pendidik dalam proses pendidikan sangat berpengaruh terhadap prestasi peserta didik. Sehingga, perlu adanya peningkatan kualitas dari pendidik terutama dalam proses pendidikan. Berlandaskan yang telah dipaparkan di atas, peneliti mengkajinya melalui penelitian mengenai supervisi kunjungan kelas untuk meningkatkan kompetensi pedagogik guru SDNegeri Cukil 01, Kecamatan Tengaran, Kabupaten Semarang.

\section{METODE PENELITIAN}

Rancangan yang diterapkan dalam penelitian ini adalah penelitian tindakan sekolah. Penelitian ini tidak menggunakan sistem siklus untuk pengambilan data, namun melalui tahap identifikasi bidang fokus, pengumpulan data, analisis dan interpretasi data, penyusunan rencana, dan pelaksanaan tindakan. Peneliti menggunakan rancangan Penelitian Tindakan Sekolah dengan skema langkah-langkah sesuai dengan gambar 1 langkah penelitian tindakan.

Subjek penelitian ini meliputi 10 guru kelas di SD Negeri Cukil 01, Tengaran. Sumber data yang digunakan peneliti melalui wawancara dengan responden, selain itu juga melalui studi dokumen. Teknik pengumpulan data yang digunakan adalah melalui pengamatan langsung pada saat guru mengajar di dalam kelas, sehingga diperlukan lembar pengamatan, untuk mendukung data pengamatan tersebut, peneliti juga melakukan wawancara dan angket untuk mengetahui respon guru terhadap pelaksanaan tindakan. Setelah data terkumpul, maka perlu adanya pengolahan data. Pengolahan data dilakukan dengan penggolongan data, penyajian data, dan verifikasi. Sedangkan untuk menguji keabsahan data, pada penelitian ini menggunakan triangulasi data yang meliputi triangulasi sumber dan triangulasi teknik. Indikator

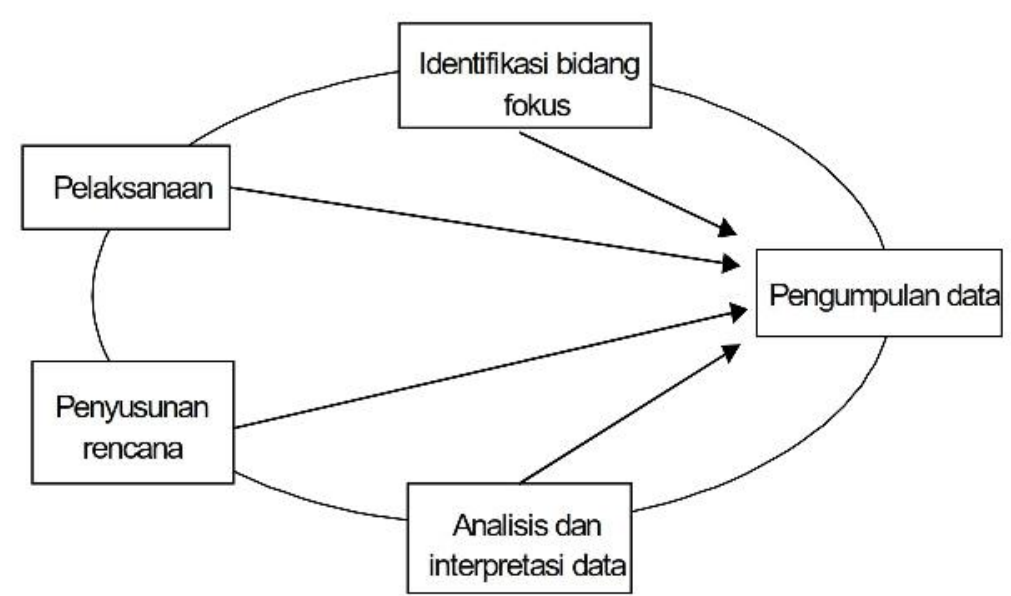

Gambar 1 Langkah-langkah Penelitian Tindakan (Sukmadinata, 2010) 
keberhasilan dalam penelitian ini adalah pelaksanaan supervisi kunjungan kelas untuk meningkatkan kompetensi pedagogik guru SDNCukil 01, Tengaran menunjukkan kriteria sekurang-kurangnya baik.

\section{HASIL PENELITIAN DAN PEMBAHASAN}

\section{Hasil Penelitian}

Berdasarkan hasil penelitian, berikut adalah hasil supervisi kunjungan kelas dan kompetensi pedagogik guru SD Negeri Cukil 01, Tengaran. Hasil supervisi kunjungan kelas terdapat tiga tahap pelaksanaannya, yaitu tahap persiapan (pra observasi), tahap pelaksanaan (observasi), dan tahap pasca observasi. Tahap pra observasi, dilakukan melalui wawancara melalui sepuluh pertanyaan yang diajukan kepada masing-masing guru. Hasil yang diperoleh menunjukkan para guru melakukan persiapan sebelum melakukan pembelajaran di dalam kelas. Perencanaan yang dilakukan meliputi menyiapkan RPP, silabus, materi pembelajaran, daftar nilai siswa, daftar hadir siswa dan media pembelajaran. Hasil wawancara tersebut, didukung dengan adanya dokumen seperti RPP untuk pelajaran hari itu, silabus, daftar hadir yang terisi dan daftar nilai dalam bentuk pengolahan. Tahap pelaksanaan (observasi) dilakukan peneliti bersama Kepala Sekolah dengan melakukan pengamatan langsung ketika guru mengajar, sehingga digunakan lembar pengamatan. Lebih jelasnya dapat dilihat pada Tabel 1 hasil pelaksanaan supervisi kunjungan kelas.

Tabel 1 menunjukkan bahwa terdapat 25 indikator yang menjadi pedoman pengukuran pelaksanaan pembelajaran guru di dalam kelas. Dalam pelaksanaan tersebut, tentunya juga disesuaikan dengan perencanaan yang telah dilakukan oleh guru terkait.
Pada tahap paska observasi, peneliti melakukan wawancara dengan para guru untuk mengukur kekuatan dan kelemahan pembelajaran yang dilakukan oleh masing-masing guru. Melalui sepuluh pertanyaan, hasil menunjukkan bahwa sebagian besar guru merasa optimis terhadap perencanaan dan pelaksanaan yang dilakukannya. Beberapa kelemahan yang dirasakan guru adalah masih lemahnya konsentrasi siswa apalagi jika kelas dalam keadaan siswa penuh. Guru juga menyusun beberapa alternatif pemecahan masalah diantaranya akan dilaksanakan pembelajaran yang inovatif, penyusunan tempat duduk yang tidak monoton, serta pelaksanaan kerja kelompok.

Pada tahap evaluasi dan balikan peneliti melakukan wawancara dan penyebaran angket sebagai alat menggali balikan. Hasilnya menunjukkan bahwa sebagian besar guru telah melaksanakan pembelajaran sesuai dengan rencana yang telah dibuat. Balikan diperoleh melalui angket dengan menyertakan 21 pertanyaan untuk mengetahui respon guru. Lebih jelas mengenai hasil balikan dapat dilihat pada tabel 2 hasil angket respon guru.

Tabel 1 menunjukkan terdapat 25 indikator yang menjadi pedoman pengukuran pelaksanaan pembelajaran guru di dalam kelas. Dalam pelaksanaan tersebut, tentunya juga disesuaikan dengan perencanaan yang telah dilakukan oleh guru terkait.

Tahap pasca observasi, dilakukan peneliti melalui wawancara dengan para guru untuk mengukur kekuatan dan kelemahan pada pembelajaran yang dilakukan oleh masingmasing guru. Melalui sepuluh pertanyaan, hasil menunjukkan sebagian besar guru merasa optimis terhadap perencanaan dan pelaksanaan yang dilakukannya. Beberapa kelemahan yang dirasakan guru adalah masih lemahnya konsentrasi siswa apalagi jika kelas dalam keadaan siswa penuh. Guru juga menyusun 
Tabel 1 Hasil Pelaksanaan Supervisi Kunjungan Kelas

\begin{tabular}{|c|c|c|c|c|c|c|c|c|c|c|c|}
\hline \multirow{2}{*}{ NO } & \multirow{2}{*}{ KOMPONEN YANG DINILAI } & \multicolumn{10}{|c|}{ KELAS } \\
\hline & & $1 \mathrm{~A}$ & $1 \mathrm{~B}$ & $2 \mathrm{~A}$ & $2 B$ & 3 & 4 & $5 \mathrm{~A}$ & $5 B$ & $6 \mathrm{~A}$ & $6 \mathrm{~B}$ \\
\hline 1 & $\begin{array}{l}\text { Tersedianya Analisis Minggu Efektif, Prota, } \\
\text { Prosem }\end{array}$ & 4 & 5 & 4 & 4 & 4 & 3 & 5 & 4 & 4 & 4 \\
\hline 2 & Tersedianya Silabus & 5 & 5 & 4 & 5 & 4 & 5 & 5 & 5 & 4 & 4 \\
\hline 3 & $\begin{array}{l}\text { Tersedianya RPP (Rencana Pelaksanaan } \\
\text { Pembelajaran) }\end{array}$ & 4 & 4 & 4 & 4 & 4 & 4 & 5 & 5 & 4 & 3 \\
\hline 4 & $\begin{array}{l}\text { Tersedianya alat peraga / media pembelajaran } \\
\text { yang relevan }\end{array}$ & 5 & 5 & 3 & 2 & 1 & 2 & 5 & 2 & 4 & 4 \\
\hline 5 & $\begin{array}{l}\text { Tersedianya daftar nil ai siswa dan diisi sesuai } \\
\text { dengan aspek }\end{array}$ & 4 & 5 & 5 & 5 & 5 & 5 & 5 & 5 & 5 & 5 \\
\hline 6 & $\begin{array}{l}\text { Tersedianya daftar hadir siswa dan diisi bukti } \\
\text { kehadirannya }\end{array}$ & 5 & 5 & 5 & 5 & 5 & 5 & 5 & 5 & 5 & 5 \\
\hline 7 & $\begin{array}{l}\text { Memeriksa kehadiran, kebersihan, dan kesiapan } \\
\text { siswa }\end{array}$ & 4 & 5 & 5 & 5 & 3 & 5 & 5 & 5 & 5 & 5 \\
\hline 8 & Menyampaikan kompetensi yang akan di capai & 4 & 3 & 4 & 4 & 4 & 5 & 5 & 5 & 5 & 5 \\
\hline 9 & $\begin{array}{l}\text { Menyampaikan indikator pencapaian kompeten } \\
\text { si dan Pengembangannya }\end{array}$ & 4 & 4 & 3 & 4 & 2 & 5 & 3 & 3 & 5 & 5 \\
\hline 10 & Melakukan apersepsi dan motivasi & 4 & 5 & 5 & 4 & 3 & 4 & 5 & 3 & 4 & 4 \\
\hline 11 & Melakukan pretes & 1 & 1 & 2 & 1 & 1 & 3 & 1 & 4 & 3 & 3 \\
\hline 12 & Menyampaikan materi secara kontekstual & 5 & 5 & 4 & 5 & 5 & 4 & 5 & 4 & 5 & 5 \\
\hline 13 & Menggunakan media peraga sesuai materi & 5 & 5 & 2 & 2 & 1 & 2 & 5 & 2 & 5 & 4 \\
\hline 14 & $\begin{array}{l}\text { Menguasai materi pelajaran dan } \\
\text { pengembangannya }\end{array}$ & 5 & 5 & 5 & 5 & 4 & 5 & 5 & 5 & 5 & 5 \\
\hline 15 & Memberi contoh-contoh secara kontekstual & 4 & 5 & 5 & 4 & 5 & 2 & 5 & 4 & 5 & 5 \\
\hline 16 & Menggunakan media peraga sesuai materi & 5 & 5 & 2 & 2 & 1 & 3 & 5 & 2 & 5 & 4 \\
\hline 17 & $\begin{array}{l}\text { Menggunakan strategi / metodologi secara } \\
\text { kontekstual }\end{array}$ & 4 & 4 & 4 & 5 & 4 & 3 & 5 & 4 & 5 & 5 \\
\hline 18 & Mengatur penggunaan waktu secara tepat & 5 & 5 & 5 & 5 & 5 & 5 & 5 & 5 & 4 & 4 \\
\hline 19 & $\begin{array}{l}\text { Mengatur dan memanfaatkan fasilitas yang } \\
\text { ada secara maksimal }\end{array}$ & 5 & 5 & 5 & 5 & 5 & 5 & 4 & 5 & 5 & 5 \\
\hline 20 & $\begin{array}{l}\text { Memberikan kesempatan pada siswa untuk } \\
\text { aktif bertanya dan menjawab }\end{array}$ & 4 & 5 & 5 & 5 & 4 & 5 & 5 & 5 & 5 & 4 \\
\hline 21 & Memonitor (menilai) tingkat pemahaman siswa & 5 & 5 & 4 & 5 & 3 & 4 & 4 & 5 & 4 & 4 \\
\hline 22 & Memberi penguatan terhadap jawaban siswa & 5 & 5 & 4 & 5 & 5 & 5 & 5 & 4 & 4 & 4 \\
\hline 23 & Menyimpulkan pelajaran & 4 & 5 & 4 & 4 & 4 & 5 & 5 & 5 & 5 & 5 \\
\hline 24 & Melaksanakan postes & 5 & 5 & 5 & 5 & 5 & 5 & 5 & 5 & 4 & 4 \\
\hline 25 & Memberikan tindak lanjut (tugas) & 5 & 5 & 5 & 4 & 5 & 5 & 5 & 5 & 4 & 4 \\
\hline & JUMLAH SKOR & 110 & 116 & 103 & 104 & 92 & 104 & 117 & 106 & 113 & 109 \\
\hline & PROSEN & $88 \%$ & $93 \%$ & $82 \%$ & \begin{tabular}{|l|}
$83 \%$ \\
\end{tabular} & $74 \%$ & $83 \%$ & $94 \%$ & $85 \%$ & $90 \%$ & $87 \%$ \\
\hline & KATEGORI & $A B$ & $A B$ & B & $B$ & B & $B$ & $A B$ & $A B$ & $A B$ & $A B$ \\
\hline
\end{tabular}

Sumber: diolah pada 24 April 2015 dari pelaksanaan Supervisi Kunjungan Kelas

beberapa alternatif pemecahan masalah diantaranya akan dilaksanakan pembelajaran yang inovatif, penyusunan tempat duduk yang tidak monoton, serta pelaksanaan kerja kelompok.

Tahap evaluasi dan balikan diperoleh melalui wawancara dan penggunaan angket sebagai balikan. Tahap evaluasi menunjukkan sebagian besar guru telah melaksanakan sesuai dengan rencana yang telah dibuat. Balikan dilakukan melalui angket dengan menyertakan 21 pertanyaan untuk mengetahui respon guru.
Lebih jelas mengenai hasil balikan dapat dilihat pada Tabel 2 hasil angket respon guru.

Tabel 2 menunjukkan sebagian besar guru memberikan respon atau balikan yang positif terhadap pelaksanaan supervisi kunjungan kelas. Tahap tindak lanjut dilakukan melalui diskusi terbuka dengan Kepala Sekolah dan para guru. Hasil dari tindak lanjut adalah pelaksanaan supervisi kunjungan kelas yang tadinya belum dilaksanakan, kini akan dilaksanakan guna memperbaiki proses pembelajaran yang 
kurang dan meningkatkan kegiatan pembelajaran yang sudah baik.

\section{Kompetensi Pedagogik}

Kompetensi pedagogik yang diukur adalah kompetensi pedagogik guru kelas. Pengukuran dilakukan melalui pengamatan langsung dengan menggunakan instrumen pengamatan. Tujuh kompetensi yang terdapat dalam kompetensi pedagogik digunakan sebagai pedoman penilaian. Hasil kompetensi pedagogik guru dapat dilihat pada tabel 3 hasil kompetensi pedagogik guru.

Hasil penelitian menunjukkan perolehan skor dalam bentuk prosen untuk masing-masing kompetensi pada masing-masing kelas. Data menunjukkan perolehan skor maksimal adalah amat baik (AB) dan minimal adalah baik (B).

Tabel 2 Hasil Angket Respon Guru

\begin{tabular}{|c|c|c|c|}
\hline \multirow[t]{2}{*}{ No. } & \multirow[t]{2}{*}{ Pertanyaan } & \multicolumn{2}{|c|}{$\begin{array}{l}\text { Jumlah Guru } \\
\text { Menjawab }\end{array}$} \\
\hline & & Ya & Tidak \\
\hline 1. & $\begin{array}{l}\text { Setelah dilakukan teknik supervisi kunjungan kelas, apakah Saudara merasa } \\
\text { terbantu? }\end{array}$ & 10 & 0 \\
\hline 2. & $\begin{array}{l}\text { Melalui teknik supervisi kunjungan kelas, apakah Saudara dapat mengetahui } \\
\text { kelemahan Saudara dalam pembelajaran? }\end{array}$ & 10 & 0 \\
\hline 3. & Apakah saudara menjadi lebih tersusun dalam pelaksanaan pembelajaran? & 10 & 0 \\
\hline 4. & Apakah Saudara menjadi lebih termotivasi dalam mengembangkan pembelajaran? & 10 & 0 \\
\hline 5. & $\begin{array}{l}\text { Apakah Saudara termotivasi dalam mengembangkan kompetensi guru dan } \\
\text { melakukan perbaikan pembelajaran? }\end{array}$ & 10 & 0 \\
\hline 6. & $\begin{array}{l}\text { Apakah Saudara dapat mengetahui kelebihan Saudara dalam melaksanakan } \\
\text { pengajaran? }\end{array}$ & 10 & 0 \\
\hline 7. & Apakah Saudara merasa senang dengan adanya supervisi kunjungan kelas ini? & 10 & 0 \\
\hline 8. & $\begin{array}{l}\text { Melalui supervisi kunjungan kelas ini, apakah Saudara menjadi lebih menguasai } \\
\text { keterampilan dalam mengajar? }\end{array}$ & 10 & 0 \\
\hline 9. & $\begin{array}{l}\text { Apakah sebelumnya Saudara sudah memahami betul mengenai kompetensi } \\
\text { pedagogik dalam pelaksanaannya? }\end{array}$ & 9 & 1 \\
\hline 10. & $\begin{array}{l}\text { Apakah menurut Saudara melalui supervisi kunjungan kelas ini dapat meningkatkan } \\
\text { kompetensi Saudara dalam mengajar? }\end{array}$ & 10 & 0 \\
\hline 11. & Apakah Saudara menghendaki adanya supervisi akademik secara terjadwal? & 10 & 0 \\
\hline 12. & $\begin{array}{l}\text { Apakah Saudara dapat merasa terbuka terhadap permasalahan selama } \\
\text { pembelajaran setelah dilaksanakan supervisi akademik ini? }\end{array}$ & 10 & 0 \\
\hline 13. & $\begin{array}{l}\text { Apakah menurut Saudara perlu adanya peningkatan kompetensi pedagogik bagi } \\
\text { pendidik? }\end{array}$ & 10 & 0 \\
\hline 14. & $\begin{array}{l}\text { Apakah melalui supervisi kunjungan kelas terjadi saling keterbukaan antara Saudara } \\
\text { dengan Kepala Sekolah? }\end{array}$ & 10 & 0 \\
\hline 15. & $\begin{array}{l}\text { Apakah melalui supervisi yang dilaksanakan meningkatkan motivasi Saudara dalam } \\
\text { melaksanakan pembelajaran? }\end{array}$ & 10 & 0 \\
\hline 16. & $\begin{array}{l}\text { Jika pelaksanaan supervisi secara rutin, apakah Saudara termotivasi untuk menjadi } \\
\text { lebih baik lagi dalam melaksanakan pembelajaran? }\end{array}$ & 10 & 0 \\
\hline 17. & $\begin{array}{l}\text { Apakah pelaksanaan supervisi kunjungan kelas membuat Saudara menjadi tidak } \\
\text { nyaman selama pembelajaran berlangsung? }\end{array}$ & 2 & 8 \\
\hline 18. & $\begin{array}{l}\text { Apakah pelaksanaan supervisi kunjungan kelas membuat peserta didik Saudara } \\
\text { menjadi tidak nyaman }\end{array}$ & 1 & 9 \\
\hline 19. & $\begin{array}{l}\text { Apakah pelaksanaan supervisi kunjungan kelas sangat menguntungkan bagi } \\
\text { Saudara? }\end{array}$ & 10 & 0 \\
\hline 20. & $\begin{array}{l}\text { Apakah umpan balik yang diberikan dapat menjadi masukan bagi Saudara untuk } \\
\text { perbaikan? }\end{array}$ & 10 & 0 \\
\hline 21. & $\begin{array}{l}\text { Apakah telah ada perbaikan yang Saudara lakukan setelah pelaksanaan supervisi } \\
\text { kunjungan kelas dalam kegiatan pembelajaran? }\end{array}$ & 10 & 0 \\
\hline
\end{tabular}

Sumber: diolah pada 25 April2015 melalui Angket 
Tabel 3 Hasil Kompetensi Pedagogik Guru

\begin{tabular}{|c|c|c|c|c|c|c|c|c|c|c|c|}
\hline \multirow{2}{*}{ No. } & \multirow{2}{*}{ Kompetensi } & \multicolumn{10}{|c|}{ Kelas (nilai konversi) } \\
\hline & & $1 \mathrm{a}$ & $1 \mathrm{~b}$ & $2 a$ & $2 b$ & 3 & 4 & $5 a$ & $5 b$ & $6 a$ & $6 b$ \\
\hline 1. & $\begin{array}{l}\text { Memahami } \\
\text { karateristik peserta } \\
\text { didik dari aspek fisik, } \\
\text { moral, spiritual, } \\
\text { sosial, kultural } \\
\text { emosional, dan } \\
\text { intelektual. }\end{array}$ & $75 \%$ & $75 \%$ & $75 \%$ & $83 \%$ & $75 \%$ & $75 \%$ & $75 \%$ & $83 \%$ & $92 \%$ & $83 \%$ \\
\hline 2. & $\begin{array}{l}\text { Menguasai teori } \\
\text { belajar dan prinsip- } \\
\text { prinsip pembelajaran } \\
\text { yang mendidik }\end{array}$ & $92 \%$ & $92 \%$ & $92 \%$ & $83 \%$ & $75 \%$ & $75 \%$ & $83 \%$ & $83 \%$ & $75 \%$ & $83 \%$ \\
\hline 3. & $\begin{array}{l}\text { Mengembangkan } \\
\text { kurikulum yang } \\
\text { terkait dengan mata } \\
\text { pelajaran yang } \\
\text { diampu. }\end{array}$ & $75 \%$ & $75 \%$ & $50 \%$ & $50 \%$ & $75 \%$ & $75 \%$ & $88 \%$ & $75 \%$ & $88 \%$ & $75 \%$ \\
\hline 4. & $\begin{array}{l}\text { Menyelenggarakan } \\
\text { pembelajaran yang } \\
\text { mendidik. }\end{array}$ & $77 \%$ & $77 \%$ & $77 \%$ & $82 \%$ & $68 \%$ & $82 \%$ & $86 \%$ & $82 \%$ & $82 \%$ & $82 \%$ \\
\hline 5. & $\begin{array}{l}\text { Mengembangkan } \\
\text { potensi peserta didik } \\
\text { untuk } \\
\text { mengaktualisasikan } \\
\text { berbagai potensi yang } \\
\text { dimiliki. }\end{array}$ & $93 \%$ & $86 \%$ & $79 \%$ & $64 \%$ & $57 \%$ & $75 \%$ & $93 \%$ & $86 \%$ & $71 \%$ & $71 \%$ \\
\hline 6. & $\begin{array}{l}\text { Berkomunikasi secara } \\
\text { efektif, empatik, dan } \\
\text { santun dengan } \\
\text { peserta didik. }\end{array}$ & $92 \%$ & $92 \%$ & $92 \%$ & $92 \%$ & $83 \%$ & $92 \%$ & $92 \%$ & $92 \%$ & $83 \%$ & $83 \%$ \\
\hline 7. & $\begin{array}{l}\text { Menyelenggarakan } \\
\text { penilaian dan evaluasi } \\
\text { proses hasil belajar }\end{array}$ & $60 \%$ & $70 \%$ & $60 \%$ & $60 \%$ & $60 \%$ & $70 \%$ & $80 \%$ & $70 \%$ & $80 \%$ & $70 \%$ \\
\hline \multicolumn{2}{|c|}{ RATA-RATA } & $81 \%$ & $81 \%$ & $75 \%$ & $73 \%$ & $70 \%$ & $76 \%$ & $88 \%$ & $82 \%$ & $82 \%$ & $78 \%$ \\
\hline \multicolumn{2}{|c|}{ KATEGORI } & $A B$ & $A B$ & B & B & B & $A B$ & $A B$ & $A B$ & $A B$ & $A B$ \\
\hline
\end{tabular}

Sumber: diolah pada 25 April2015 melalui Angket

Berdasar data awal penelitian yang dilakukan melalui wawancara dengan Kepala Sekolah dan guru dengan menyertakan instrumen kompetensi pedagogik guru, secara umum dari tujuh kompetensi yang ada menunjukkan kompetensi guru memperoleh kriteria baik (B). Kepala Sekolah juga menjelaskan bahwa selama ini kompetensi pedagogik belum memperoleh perhatian khusus, karena penilaian hanya dilakukan melalui PKG. Oleh karena itu, peneliti menyusun rencana dengan menentukan alat bantu yang tepat guna meningkatkan kompetensi guru. Melalui supervisi kunjungan kelas yang sebelumnya belum dilaksanakan dipilih peneliti sebagai alat bantu meningkatkan kompetensi pedagogik guru. Peningkatan kompetensi pedagogik dapat dilihat pada gambar 2 peningkatan kompetensi pedagogik. 


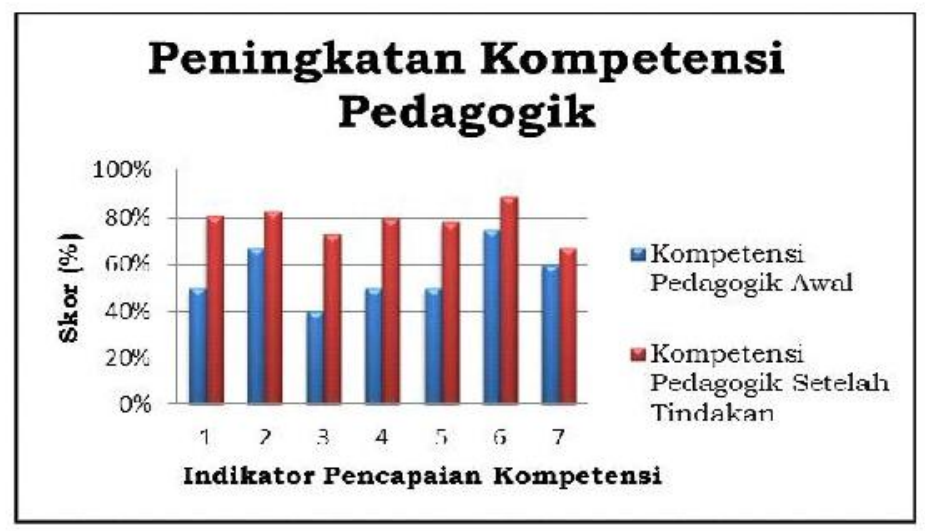

Gambar 2 Peningkatan Kompetensi Pedagogik

Setelah dilaksanakan penelitian, menunjukkan bahwa melalui pelaksanaan supervisi kunjungan kelas, maka akan dapat terukur pula kompetensi pedagogik guru. Data yang diperoleh melalui penelitian menunjukkan, perolehan skor supervisi kunjungan kelas yang baik akan diikuti perolehan skor kompetensi pedagogik yang baik pula. Lebih jelasnya dapat dilihat tabel 4 skor supervisi kunjungan kelas dan kompetensi pedagogik.

Berdasar tabel yang disajikan, menunjukkan perolehan skor supervisi kunjungan kelas dan kompetensi pedagogik untuk masingmasing kelas dalam bentuk prosen (\%). Perolehan skor supervisi kunjungan kelas yang menunjukkan 6 dari 10 guru kriteria amat baik (AB) dan 4 lainnya kriteria baik (B) diikuti dengan perolehan skor kompetensi pedagogik yang sebanding. Lebih jelasnya, dapat dilihat pada gambar 3 diagram yang menunjukkan perolehan skor supervisi kunjungan kelas dan kompetensi pedagogik guru masing-masing kelas.

Dari Gambar 3 dapat disimpulkan berdasarkan diagram, bahwa pelaksanaan supervisi kunjungan kelas dapat meningkatkan kompetensi pedagogik guru.

\section{PEMBAHASAN}

Pelaksanaan supervisi kunjungan kelas yang meliputi pra observasi, observasi, pasca observasi, evaluasi dan balikan, dan tindak lanjut yang telah dilakukan selaras dengan penelitian yang dilakukan oleh Ni Nengah

Tabel 4 Skor Supervisi Kunjungan Kelas dan Kompetensi Pedagogik

\begin{tabular}{ccccc}
\hline Kelas & $\begin{array}{c}\text { Skor } \\
\text { Supervisi Kunjungan Kelas } \\
(\%)\end{array}$ & $\mathrm{K}$ & $\begin{array}{c}\text { Skor } \\
\text { Kompetensi Pedagogik } \\
(\%)\end{array}$ & $\mathrm{K}$ \\
\hline 1A & 88 & $\mathrm{AB}$ & 81 & $\mathrm{AB}$ \\
$1 \mathrm{~B}$ & 93 & $\mathrm{AB}$ & 81 & $\mathrm{AB}$ \\
$2 \mathrm{~A}$ & 82 & $\mathrm{~B}$ & 75 & $\mathrm{~B}$ \\
$2 \mathrm{~B}$ & 83 & $\mathrm{~B}$ & 73 & $\mathrm{~B}$ \\
3 & 74 & $\mathrm{~B}$ & 70 & $\mathrm{~B}$ \\
4 & 83 & $\mathrm{~B}$ & 76 & $\mathrm{AB}$ \\
$5 \mathrm{~A}$ & 94 & $\mathrm{AB}$ & 88 & $\mathrm{AB}$ \\
$5 \mathrm{~B}$ & 85 & $\mathrm{AB}$ & 82 & $\mathrm{AB}$ \\
$6 \mathrm{~A}$ & 90 & $\mathrm{AB}$ & 82 & $\mathrm{AB}$ \\
$6 \mathrm{~B}$ & 87 & $\mathrm{AB}$ & 78 & $\mathrm{AB}$ \\
\hline
\end{tabular}

Sumber: diolah pada 29 April 2015 


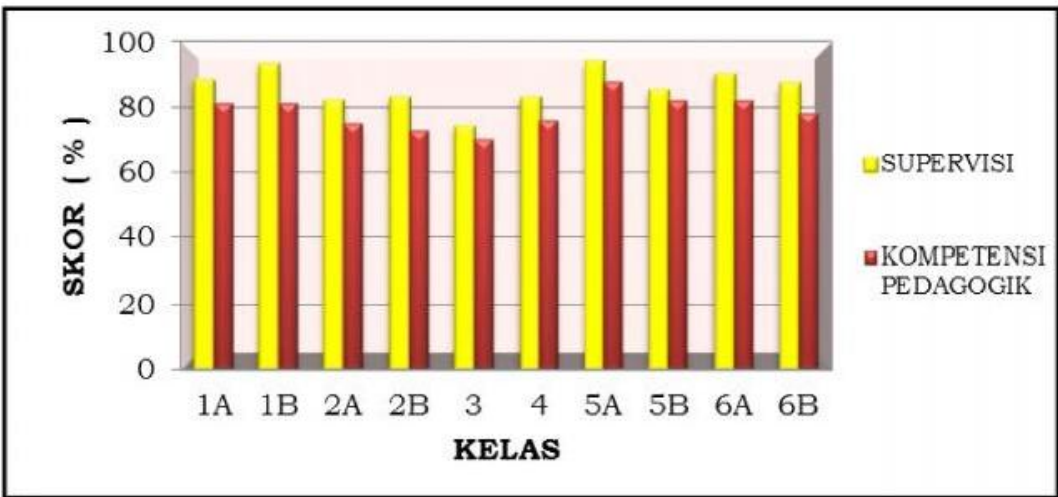

Gambar 3. Hasil Supervisi Kunjungan Kelas dan Kompetensi Pedagogik Guru Masing-masing kelas

Sumber: Hasil data pengolahan 29 April 2015

Widyani pada tahun 2011. Perbedaannya adalah pada penelitian Ni Nengah Widyani menggabungkan supervisi melalui tanya jawab individual, jika dalam penelitian ini semua terangkum dalam satu supervisi kunjungan kelas, selain itu terdapat tindak lanjut yang tidak dilakukan pada penelitian pendukung. Hasil yang diperoleh sama menunjukkan adanya hal positif terhadap pelaksanaan supervisi kunjungan kelas.

Pelaksanaan pengamatan terhadap kompetensi pedagogik guru dengan menggunakan tujuh kompetensi sebagai pedoman pengukuran selaras yang tercantum dalam Priatna dan Sukamto (2013). Sedangkan jika dibandingkan dengan penelitian pendukung mengenai kompetensi pedagogik guru, terdapat perbedaan, seperti penelitian yang dilakukan oleh Karin Apelgren dan Birgitta Giertz, 2010 dengan judul penelitian, "Pedagogical Competence - A Key to Pedagogikal Development and Quality in HigherEducation". Pada penelitian pendukung ini lebih menjelaskan kompetensi pedagogik secara deskriptif yang bertujuan untuk perkembangan dalam pekerjaannya berkenaan dengan kompetensi pedagogik untuk menambah, menciptakan kualifikasi dan penilaian yang lebih teliti mengenai kompetensi pedagogik yang berhubungan dengan jabatan dan kemajuan. Sehingga lingkup yang digunakan dalam penelitian pendukung mengenai kompetensi pedagogik lebih luas secara umum, sedangkan pada penelitian ini kompetensi pedagogik yang digunakan adalah kompetensi pedagogik guru kelas.

\section{SIMPULAN DAN SARAN}

\section{Simpulan}

Berdasar hasil penelitian yang dilakukan memperoleh data sebagai berikut:

a. Kompetensi pedagogik pada awalnya kurang mendapat perhatian, ditunjukkan perolehan skor secara umum berdasarkan tujuh kompetensi sebagai indikator kriteria secara umum adalah baik (B);

b. Melalui pelaksanaan supervisi kunjungan kelas, kompetensi pedagogik pada pengamatan menunjukkan tujuh dari sepuluh guru memperoleh kriteria amat baik $(\mathrm{AB})$ dengan skor maksimal $88 \%$ dan tiga guru lainnya memperoleh kriteria baik (B) dengan skor minimal $70 \%$.

Sehingga diperoleh simpulan bahwa supervisi kunjungan kelas dapat meningkatkan kompetensi pedagogik guru SD Negeri Cukil 01, 
Tengaran. Hal ini terjadi karena dalam pelaksanaan supervisi kunjungan kelas, beberapa indikator mencakup indikator dalam kompetensi pedagogik guru. Sehingga, dengan tercapainya supervisi yang baik, akan diiringi kompetensi pedagogik yang baik pula.

\section{Saran}

Berdasarkan hasil penelitian yang telah dilaksanakan mengenai peningkatan komptensi pedagogik guru melalui supervisi kunjungan kelas, saran yang dapat diberikan adalah sebagai berikut:

a. Bagi Kepala Sekolah, agar dapat menciptakan hubungan yang saling terbuka antara guru dengan Kepala Sekolah dalam berbagai masalah yang terjadi selama pembelajaran berlangsung, hendaknya guru dan Kepala Sekolah membuat kesepakatan untuk melaksanakan supervisi secara terjadwal.

b. Bagi guru, menanamkan sikap saling terbuka untuk dapat saling berkomunikasi antar guru mengenai masalah pembelajaran. Akan lebih baik jika ikut aktif dalam kegiatan peningkatan kualitas pembelajaran baik yang diadakan sekolah maupun dinas.

c. Bagi Sekolah, akan lebih baik jika diadakan kegiatan bagi para guru untuk dapat melakukan perencanaan pembelajaran secara efektif dan efisien. Demikian halnya dalam pelaksanaan pembelajaran dengan menggunakan berbagai strategi pembelajaran, agar dapat menciptakan kondisi pembelajaran sesuai dengan yang diharapkan.

\section{DAFTAR PUSTAKA}

Apelgren, Karin and Birgitta Giertz. 2010. Pedagogical competence - a key to Pedagogical development and quality in Higher education. Uppsala University: Division for Development of Teaching and Leaming.

LPMP. 2012."1.840 Guru Jawa Tengah TakLulus UKA", http://www.lpmpjateng.go.id

Permendiknas RINomor 16 Tahun 2007 Tentang Standar Kualifikasi Akademik dan KompetensiGuru.

Priatna, Nanang dan Tito Sukamto. 2013. Pengembangan Profesi Guru. Bandung: PT. Remaja Rosdakarya.

Sukmadinata, Syaodih Nana. 2010. Metode Penelitian Pendidikan. Bandung: PT Remaja Rosdakarya.

Undang-Undang Nomor 14 Tahun 2005 Tentang Guru dan Dosen.

Undang-Undang Sistem Pendidikan Nasional Nomor 20 Tahun 2003.

Widyani, Nengah Ni. 2011. Teknik Supervisi Kunjugan Kelas Sebagai Upaya Meningkatkan Kompetensi Profesional. WIDYATECH Jurnal Sains dan Teknologi Vol. 11 No. I Agustus 2011. 